\title{
Study on Information System Architecture Based on Service-Dominant Logic
}

\author{
Juhua Wu1 ${ }^{1}$ Meng Xu2* ${ }^{2 *}$ Zan Mo1, Nuo Liao' \\ ${ }^{1}$ School of Management, Guangdong University of Technology, Guangzhou, China \\ ${ }^{2}$ Graduate Students of Electronic Commerce, Guangdong University of Technology, Guangzhou, China \\ Email: $619867554 @ q q . c o m$
}

Received 23 January 2015; accepted 12 February 2015; published 15 February 2015

Copyright (C) 2015 by authors and Scientific Research Publishing Inc.

This work is licensed under the Creative Commons Attribution International License (CC BY). http://creativecommons.org/licenses/by/4.0/

(c) (i) Open Access

\begin{abstract}
As goods-dominant logic lexicon transitions to service-dominant logic, based on the knowledge and structure dimensions of IT and business alignment, combined with the IT flexible, we design information system architecture diagram of y group. We try to solve y group functionality and data misfit domains, aligning information system and business in operational level to response to changes in the environment.
\end{abstract}

\section{Keywords}

\section{Service-Dominant Logic, IT and Business Alignment, System Architecture}

\section{Introduction}

As goods-dominant logic lexicon is replaced by service-dominant logic, scholars focus from the exchange value to the service management [1]. In the service-dominant logic, service is the foundation of all economic exchange. Customers create useful value [2], and apart from providing products, companies take the product as the carrier of services provided to clients.

In the 21st century, the strategy has changed towards offering more services [3]. Thereby, enterprise information technology has also changed the support for business, which transits IT delivery from the product-oriented mode to the service-oriented mode. Sauer and Yetton [4] argue that IT should manage in a way that reflects the management of the business, rather than simulate manual business. In addition, too narrowly customize IT systems to meet current business needs, resulting in an inflexible infrastructure that does not reflect standards and is costly to update [5]. It is necessary to rethink of information system planning.

The features of service-oriented architecture (SOA) include loose coupling, abstraction, and reusability and

*Corresponding author. 
composability [6], which can adapt to the continuous forward of technology [7] and the external market dynamics. In addition, IT can provide firms with the flexibility to respond to opportunities in the environment by enabling the firm to realign in response to an environmental change, quickly innovating and reconfiguring its core activities to apply to new opportunities [8]. In service-dominant logic, especially in the logistics industry, the research of group information system architecture at the operational level is less, which remains to be further discussed.

The remainder of this paper is arranged as follows. We first describe the connotation of the alignment, synthesizing a diverse body of literature to present the definition, level and dimension of alignment. Next, we introduce IT flexibility, including the origin, attribute and implication of flexibility. Then, based upon this literature review, we design information system architecture diagram of y group, aligning information system and business. After discussing our results, we conclude by assessing the limitations of our research and suggesting potential avenues for future research.

\section{The Connotation of the Alignment}

The concept of alignment between business and IT first emerged early in the 1970s [9]. We adopt the definition of Henderson and Venkatraman [10] on alignment between business and IT strategies: “Alignment between business and IT is the degree of fit and integration between business strategy, IT strategy, business infrastructure, and IT infrastructure.” IT affects every level of the business organization, such as the strategic layer, operational layer, and project layer, etc. Strategic alignment is defined as "the degree to which the mission, objectives, and plans contained in the business strategy are shared and supported by the IS strategy” [11]. Operational alignment is defined as "the link between organizational infrastructure and processes and IS infrastructure and processes" [12]. Project alignment is defined as "the degree to which information systems are accepted by enterprise internal individual employee” [13].

Chan and Reich [14] provided several dimensions of alignment: strategic/intellectual, structural, social, and cultural. This paper mainly discusses intellectual and structural dimensions.

\subsection{Intellectual Dimension}

Intellectual alignment refers to the degree to which the business strategy and plans, and the IT strategy and plans, complement each other [14]. This dimension emphasizes IT and business objectives in a consistent state and concentrates on the method of forming IT mission, objectives, and plans [15], including Business System Planning, Critical Success Factors, Service-Oriented Architecture (SOA), etc. This paper mainly introduces the SOA model.

SOA is a software architecture that implements business processes or services by using a set of loosely coupled, black-box components orchestrated to deliver a well-defined level of service, regardless of the machine and languages used for service execution and description [16]. SOA standard integrates application systems, making the enterprise to better respond to market changes.

\subsection{Structural Dimension}

Structural alignment refers to the degree of structural fit between IT organization structure and the business organization structure [10]. The key factors affecting structural dimension include [15] CIO position, CIO reporting relationships, centralization (decentralized) of IT and decision-making power of IT, etc.

IT structure should also align organize environment and business strategy [17]. IT structure highly correlated with the enterprise competition strategy. Companies that have a conservative strategy tend to have a centralized IT structure, while companies that are more entrepreneurial and risk-taking tend to have a decentralized IT structure. Brown and Magill [18] proposed a simpler structural typology involving IT structures that are centralized, decentralized, or hybrid. The structure typology depends on the enterprise diversification strategy, enterprise structure, and IT management, etc.

In this section, the definition, levels and dimensions have been discussed. Alignment allows IS and business executives to identify opportunities for IT, IT infrastructure flexibility is what will ultimately execute these opportunities. Next, we introduce IT flexibility. 


\section{IT Flexibility}

The flexibility perspective originates from Schumpeter's [19] classic concept of creative destruction, in which old practices, businesses, and industries are continually replaced by new ones. The theory of flexible highlighted that company's rapid response ability to change.

IT infrastructure flexible contains two properties: scalability and adaptability [20]. Scalability means that firms can add or remove hardware capacity, software licenses, or network bandwidth easily and quickly. Adaptability refers to the extent to which an IT infrastructure can support different IT needs, integrating data from different applications through ERP systems or middleware and whether applications can be ported to different operating systems without undergoing translation. On the basis of scalability and adaptability, IT infrastructure flexible creates digital options [8], which help to transform how IT aligns with changes in business strategy.

Tallon and Pinsonneault [21] suggested that company can define IT resources to mitigate IT architecture flexible, which help speed up the alignment with the ideal change.

In this section, we mainly discuss the source, properties, effect of IT flexibility.

\section{Y Company Information System Architecture Diagram Design}

\subsection{Background}

Y group as a logistics enterprise, after ten years of informatization construction, transformed from the auxiliary support of business to the production system development. Now based on the electronic channel application, y group has gradually transformed from production support to localization service. The current information system design of y group is layered architecture design, existing some problems: the difficulty of information query, cascading changes, system expansion, etc. Furthermore, some system are developed on single application demand, imposing information isolated island, scattered data, etc.

Strong and Volk of [22] presented the six misfit domains: functionality, data, usability, role, control and organizational culture. We mainly consider y group's misfit problems existing in the operational level, including functionality and data, and these misfit problems can be divided into business and system problems, as shown in Table 1.

In view of above problems, when design information system architecture diagram y group should pay attention to the two principles: speed and service. On the one hand, y group may quickly carry out the work by rapid response. On the other hand, y group needs to return to the community service, and focus mainly on customer experience.

\subsection{Information System Architecture Diagram}

According to existing problems of y group, we rethink its information system planning and design information system architecture diagram in the operational level to support the development of the business, as shown in Figure 1.

Information system architecture diagram can be divided into production platform, comprehensive management platform, data exchange center and channel. Production platform, as a cohesive business hub of sales and production operations, mainly positions on channel service management and business management, which consists of five parts: channel service management system, business operation center, business sales management system, customer relationship management system and operation monitoring system. Comprehensive management platform meets the demand of enterprise management control and resources control, and mainly positions on management control and decision analysis, which consists of three parts: personalized business services subsystem, enterprise resource service subsystem and decision analysis system. Data exchange center, as an information resource management platform, mainly collects data related logically to enterprises, including plan data, transaction data, archive data, statistical data. Meanwhile, according to the demand of operations management, master data and metadata are identified to collect and exchange. Channel refers to provide electronic channels or partners with access and communication platform, which consists of three parts: sales channels, self-service channels and the third party channel. Next, we detail the role of each system.

As goods-dominant logic lexicon turning to service-dominant logic, service management becomes focus. y group's products are delivered to customers in the form of distribution, reflected in business sales management system. We design customer relationship management system to delivery service to customers in the form of direct 
Table 1. y group’s problems.

\begin{tabular}{|c|c|c|}
\hline Problem & Category & Detailed description \\
\hline \multirow{2}{*}{$\begin{array}{l}\text { Business } \\
\text { problems }\end{array}$} & Functionality & $\begin{array}{l}\text { I) Service ability and innovation ability need to be improved. } \\
\text { II) Indicators monitoring ability need to be further improved. }\end{array}$ \\
\hline & Data & $\begin{array}{l}\text { III) Scattered data need to be further integrated. } \\
\text { IV) Customer multi-dimensional analysis needs to be strengthened. }\end{array}$ \\
\hline \multirow[t]{2}{*}{$\begin{array}{l}\text { System } \\
\text { problems }\end{array}$} & Functionality & $\begin{array}{l}\text { V) There are some difficulties in docking business information in electronic channel, and order } \\
\text { flow is depended on manual handling. } \\
\text { VI) Because of the multi-channel, there is lack of coordination between business, sales and order } \\
\text { information. } \\
\text { VII) Operational system lack of controls in a global perspective. } \\
\text { VIII) The function between self-built system and provincial company system is gradually overlapped. } \\
\text { IX) Products, orders, customers and channel information provided to decision-making support } \\
\text { are scattered. } \\
\text { X) There is lack of information system for decision-making, generating decision information } \\
\text { transmission time slowly. }\end{array}$ \\
\hline & Data & $\begin{array}{l}\text { XI) Business unit independent accounting, which is unfavorable for contrast. } \\
\text { XII) There are some analysis function shortcomings combined with the production and } \\
\text { management. }\end{array}$ \\
\hline
\end{tabular}

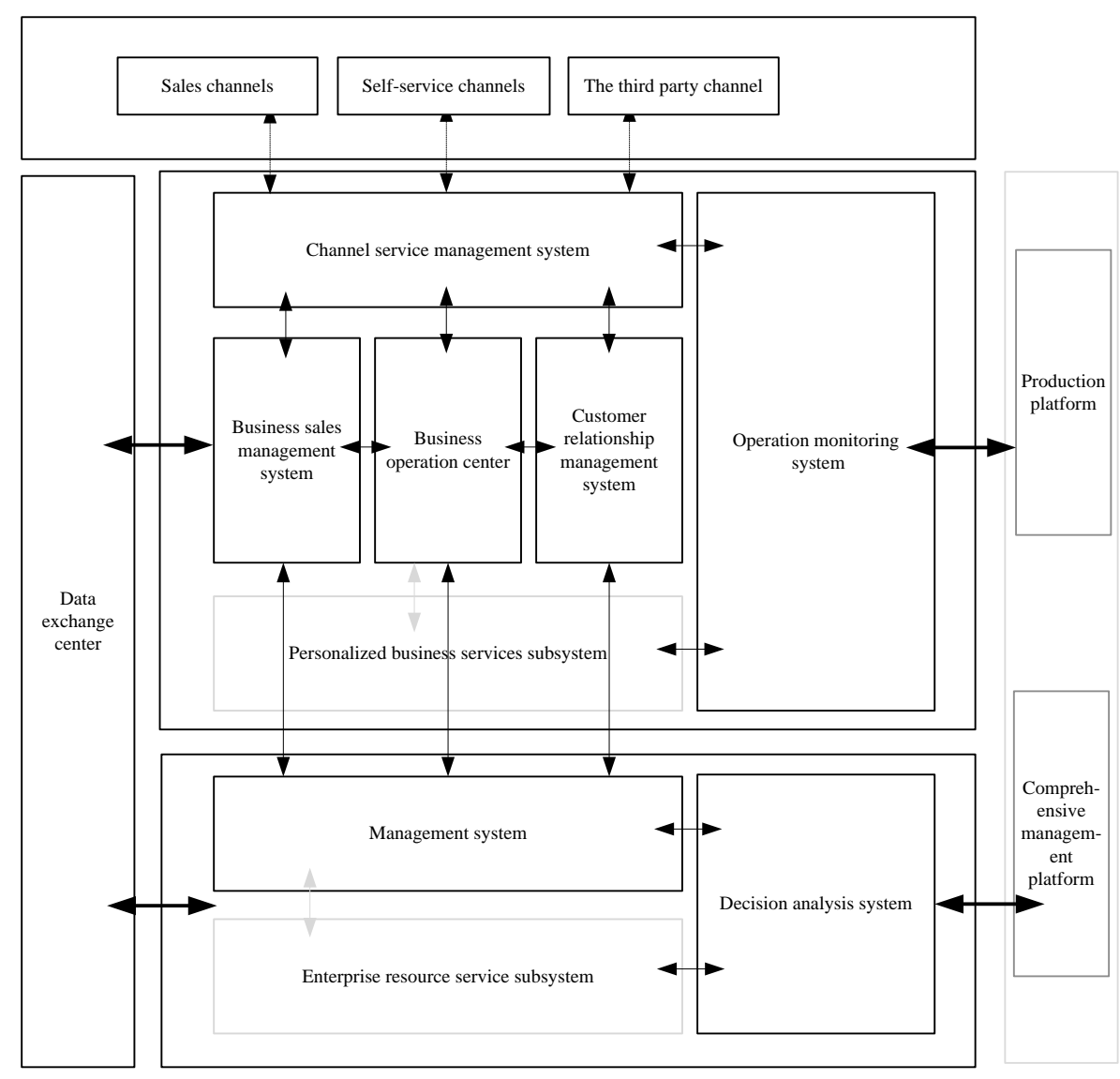

Figure 1. Information system architecture diagram.

marketing and follow customer manager so that customer experience are improved, thus Problem I solved. In addition, customer relationship management system realized centralized management of the customer resources, which provided basis for customer multi-dimensional analysis, thus Problem IV solved. The new data exchange center realized centralized storage of data and transmitted relevant data to production or management system via interface to further improve business analysis ability, thus Problems I and IX solved. 
As a conservative company, y group should adopt centralized structure of IT, reflected in channel service management system, business operation center, operation monitoring system and management system. Channel service management system connected channels via interface and realized unified interactive window of information, business and order, thus Problems III and VI solved. Business operation center connected personalized business services subsystem via interface, which not only realized unified management view of business order and standardization management of production accounting, but also realized order automation allocation instead of manual operation, thus Problems III, V, VII and XI solved. Operation monitoring system realized channels in advance warning, operation monitoring during the process of production and unified management of abnormal orders, thus Problems II and III solved. Management system realized unified management of product/service and operation accounting, and managed business in a global perspective, thus Problems III, IX and XII solved.

Due to unpredictable environmental changes, we design information system architecture diagram on the basis of SOA and IT flexibility, reflected in personalized business services subsystem and enterprise resource service subsystem. We divided customer-oriented production system into channels and unified access to channel service management system; the rest process of the production system packaged as a service was placed in personalized business services subsystem group. In order to quickly response to the future environmental change and reduce the system construction of homogeneity, these subsystem can be dynamically assembled to an integrated application program on business demand, thus Problem VIII solved. New customer, channel and customer manager unit of enterprise resource service subsystem stored these history information provided for decision analysis, thus Problem IX solved. In the meantime, we design a decision analysis system to make data analysis according to information provided by management system and enterprise resource service subsystem, thus Problem X solved.

In this section, we design information system architecture diagram of y group at the operational level, trying to solve functionality and data misfits.

\section{Conclusions}

In order to align information system and business strategy, information system planning and traditional management method need to be simultaneously adjusted. Because one way of achieving alignment is the development of information system that meets business needs [17], this paper takes y group as an example, collecting misfit information and classifying those misfits as either function misfits or data misfits. Then we combined both alignment and flexibility theory to design information system architecture diagram of y group at the operational level, which enhanced flexibility and reusability of system to response to environmental changes.

Like all studies, our work is not without limitations. Specifically, we found relatively few studies examined the operational dimensions of alignment and previous studies mainly discussed a service oriented architecturebased solution for strategic alignment [23]. In addition, the previous literatures on information system planning of logistics group are less.

In summary, our purpose in this paper was to design information system architecture diagram of y group at the operational level and solve questions of function misfits and data misfits. But we didn't study misfits on other dimensions, such as usability, role, control and organizational culture. Therefore, future research can be conducted on merging IT planning at the operational level of the business organization, further to solve other misfits.

\section{Fund}

This study is funded by National Natural Science Foundation of China: 71301030, State Oceanic Administration People’s Republic of China: GD2013-D01-001.

\section{References}

[1] Vargo, S.L. and Lusch, R.F. (2008) Service-Dominant Logic: Continuing the Evolution. Journal of the Academy of Marketing Science, 36, 1-10. http://dx.doi.org/10.1007/s11747-007-0069-6

[2] Zhong, Z.D. and Tang, S.L. (2014) The Research of Value Co-Creation Based on Service-Dominant Logic. Soft Science, 28, 31-35.

[3] Ullah, A. and Lai, R. (2013) Requirements Engineering and Business/IT Alignment: Lessons Learned. Journal of 
Software, 8, 1-10.

[4] Sauer, C., Yetton, P.W. and Alexander, L. (1997) Steps to the Future: Fresh Thinking on the Management of IT-Based Organizational Transformation. Jossey-Bass Inc., San Francisco.

[5] Shpilberg, D., Berez, S., Puryear, R. and Shah, S. (2007) Avoiding the Alignment Trap in IT. MIT Sloan Management Review, 49, 51-58.

[6] Xu, X.M. (2013) The Research of Intergration of Range Information System Based on SOA. Journal of Telemetry, Tracking and Command, 34, 72-76.

[7] Bharadwaj, A., El Sawy, O.A., Pavlou, P.A. and Venkatraman, N. (2013) Digital Business Strategy: Toward a Next Generation of Insights. MIS Quarterly, 37, 471-482.

[8] Sambamurthy, V., Bharadwaj, A. and Grover, V. (2003) Shaping Agility through Digital Options: Reconceptualizing the Role of IT in Contemporary Firms. MIS Quarterly, 27, 237-263.

[9] Luftman, J.N., Lewis, P.R. and Oldach, S.H. (1993) Transforming the Enterprise: The Alignment of Business and Information Technology Strategies. IBM Systems Journal, 32, 198-221. http://dx.doi.org/10.1147/sj.321.0198

[10] Henderson, J.C. and Venkatraman, N. (1993) Strategic Alignment: Leveraging Information Technology for Transforming Organizations. IBM Systems Journal, 32, 4-16. http://dx.doi.org/10.1147/sj.382.0472

[11] Chan, Y.E., Sabherwal, R. and Thatcher, J.B. (2006) Antecedents and Outcomes of Strategic IS Alignment: An Empirical Investigation. IEEE Transactions on Engineering Management, 53, 27-47. http://dx.doi.org/10.1109/TEM.2005.861804

[12] Henderson, J.C. and Venkatraman, H. (1999) Strategic Alignment: Leveraging Information Technology for Transforming Organizations. IBM Journal of Research and Development, 38, 472-484.

[13] Qi, X.Y. (2011) The Empirical Research of Information Technology Fusion and Its Impact on Organizational Performance. Jilin University, Changchun.

[14] Chan, Y.E. and Reich, B.H. (2007) IT Alignment: What Have We Learned. Information Technology, 22, 297-315. http://dx.doi.org/10.1057/palgrave.jit.2000109

[15] Zhang, Y.L., Xiao, J.H. and Xie, K. (2014) Information System and Business Strategy Alignment Research Review. Management Review, 4, 154-165.

[16] Li, X.J. and Zhang, M.Y. (2007) The Research of Logistics Information System Architecture Based on SOA. Logistics Technology, 26, 104-107.

[17] Ullah, A. and Lai, R. (2013) A Systematic Review of Business and Information Technology Alignment. ACM Transactions on Management Information Systems, 4, 1-30. http://dx.doi.org/10.1145/2445560.2445564

[18] Brown, C.V. and Magill, S.L. (1994) Alignment of the IS Functions with the Enterprise: Toward a Model of Antecedents. MIS Quarterly, 18, 371-403. http://dx.doi.org/10.2307/249521

[19] Schumpeter, J.A. (1934) The Theory of Economic Development. Harvard University Press, Cambridge.

[20] Drnevich, P.L. and Croson, D.C. (2013) Information Technology and Business-Level Strategy: Toward an Integrated Theoretical Perspective. MIS Quarterly, 37, 483-509.

[21] Tallon, P.P. and Pinsonneault, A. (2011) Competing Perspectives on the Link between Strategic Information Technology Alignment and Organizational Agility: Insights from a Mediation Model. MIS Quarterly, 35, 463-486.

[22] Strong, D.M. and Volkoff, O. (2010) Understanding Organization-Enterprise System Fit: A Path to Theorizing the Information Technology Artifact. MIS Quarterly, 34, 731-756.

[23] Haki, M.K. and Forte, M.W. (2010) Proposal of a Service Oriented Architecture Governance Model to Serve as a Practical Framework for Business-IT Alignment. Proceedings of the 4th International Conference on New Trends in Information Science and Service Science (NISS), Gyeongju, 11-13 May 2010, 410-417. 